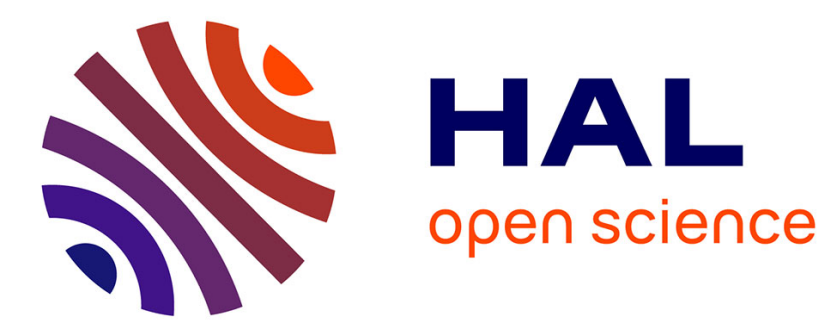

\title{
Technology and culture and possibly vigilance too
}

C. T. A. Schmidt

\section{- To cite this version:}

C. T. A. Schmidt. Technology and culture and possibly vigilance too. AI \& Society: Knowledge, Culture and Communication, 2011, 26 (4), pp.371-375. 10.1007/s00146-011-0320-z . hal-01061408

\section{HAL Id: hal-01061408 \\ https://hal.science/hal-01061408}

Submitted on 5 Sep 2014

HAL is a multi-disciplinary open access archive for the deposit and dissemination of scientific research documents, whether they are published or not. The documents may come from teaching and research institutions in France or abroad, or from public or private research centers.
L'archive ouverte pluridisciplinaire HAL, est destinée au dépôt et à la diffusion de documents scientifiques de niveau recherche, publiés ou non, émanant des établissements d'enseignement et de recherche français ou étrangers, des laboratoires publics ou privés. 


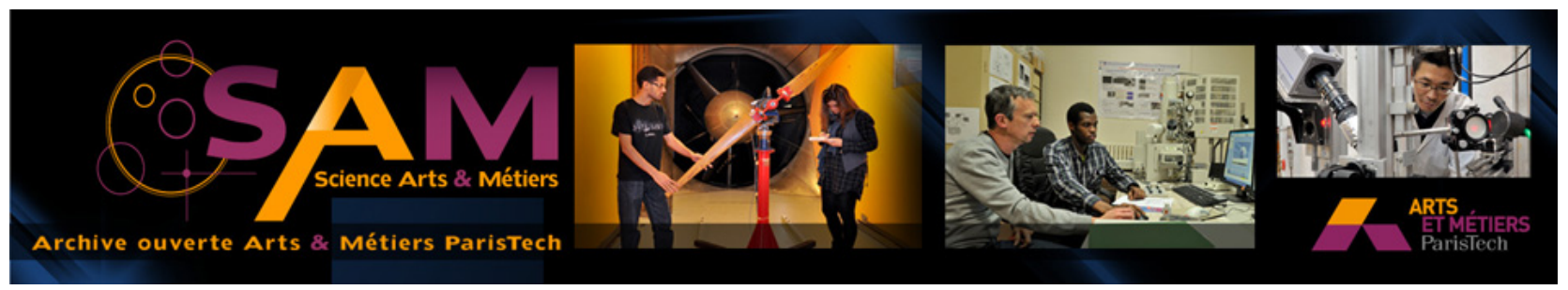

Science Arts \& Métiers (SAM)

is an open access repository that collects the work of Arts et Métiers ParisTech researchers and makes it freely available over the web where possible.

This is an author-deposited version published in: http://sam.ensam.eu Handle ID: .http://hdl.handle.net/10985/8470

\section{To cite this version :}

C. T. A. SCHMIDT - Technology and culture and possibly vigilance too - AI \& SOCIETY - Vol. 26, $n^{\circ} 4$, p.371-375 - 2011 


\title{
Technology and culture and possibly vigilance too
}

\author{
C. T. A. Schmidt
}

\begin{abstract}
Many have bowed before the recently acquired powers of 'new technologies'. However, in the shift from tekhnē to tekhnologia, it seems we have lost human values. These values are communicative in nature as technological progress has placed barriers like distance, web pages and 'miscellaneous extras' between individuals. Certain values, like the interpersonal pleasures of rendering service, have been lost as their domain of predilection has for many become fully commercially oriented, dominated by the cadence of profitability. Though the popular cultures of the artificial have surged forth to deliver us from the twentieth century, they have enabled some very superfluous dreaming-Man has succumbed to the Godly role of simulating himself and creating other beings. Communication is replaced by machines, services are rendered via many automated devices, procreation has entered the public sphere, robots and entertainment agents educate our youth and mesmerising screen-integrating 'forms of intelligence' even think for us. As such, this so-called culture threatens the very values Man constructed in the nineteenth and twentieth centuries to guide himself into the future. But what if the phenomena mentioned just reflect our new values? The author presents an investigation into this cultural shift, its impact on human practices with regards the mind and the body and evokes some pros and cons of generally accepting the 'Culture of the Artificial'.
\end{abstract}

Keywords Artefacts - Difference - Epistemology · Diversity (human) - Identity · Relation · Personhood . Philosophy (analytical) · Transhumanism

C. T. A. Schmidt ( $($ )

Le Mans University \& ENSAM-ParisTech Angers, Laval, France

e-mail: Colin.Schmidt@univ-lemans.fr

\section{Introduction}

When it comes to the production of artefacts, our environment-rich with technical objects-turns us into artefacts; in the current context, our pathological obsession on technological conformism may lead one to think of oneself as an artefact (during an invited (2011) talk in French entitled "La communication transhumaniste? Discernements et défis" at the 1st Conference of the French Transhumanistic Society, I gave examples of this logic which actually stem from Schmidt 2005, 2006 and 2007). This may sound strange but people do indeed generally try to remodel their daily lives, capabilities and appearances to keep up with others around them, as just anyone may notice. Question: Should biodiversity studies include the redesigning of Man? Regardless of the way one decides to answer here, it would seem obvious that man's simulating himself has become a culture, or even a religion. The scientific references for new future situations do not often directly portray this activity as being ritualised. My personal observation from over the last 15 years allows me to confirm this tendency about Man's self-simulation. Cultural variations on such activity do exist and are too abundant to treat here.

The way I see things, the artefactualisation of the human species may be considered part of the evolutionary process. Some may not agree with this statement; for many, the matter dealt with herein appears ideological or perhaps irrelevant to down-to-earth daily concerns... for the time being. I intend to explore the types of arguments put forth on both sides of the equation in order to illustrate the incomprehension that exists between the protagonists responding from opposing viewpoints with regard to the question of whether or not we should redesign the human being, a fast growing issue. 
More specifically, I will address issues involving advanced Artificial Intelligence, Humanoid Robotics and Transhumanism without wishing to put forth a decision why we should or should not accept new forms of life similar to our present state or those that deviate from it. This said, uprising nations should particularly be wary of deviant grassroots industrial practices (such as organ farming or operations that do not reflect the standards of the Establishment), now and in the future. Since the nature of body or personhood change is limited in some movements to behavioural or physical aspects, the actual change seems spectacular (i.e. a smart silicon implant) in comparison with changing one's body through exercise. The reader will not find any statistics here, just facts and principles about modifications aiming towards new creations (i.e. ethically impacted material such as female feticide are left out as it does not constitute an improvement on the being in question, but rather just an 'existential preference'.

\section{Techniques for human modification}

What this means is that there are basically two approaches to going about the artefactualisation of the human species. In fact, the evolutionary process itself has changed and possibly further diversification of it may come about especially if humans play a role in guiding evolution. The current two approaches are separate in that their starting points are not the same. On the one hand, the roboticsbased approach generally uses many components that are mechanical in nature (traditional hardware) though there is a growing tendency to accept organic elements into these constructions. The reasons for using organic stuffs in the robotics sphere of intervention in society are various: either they are less costly, increase functionality, render the resulting 'machine' more lifelike, less harmful to the environment, or they provide jobs to the local workforce. On the other hand, the transhumanist approach begins rebuilding man with one single very familiar component, the human body_ just like yours or mine-assuming it is fully natural. The idea is to use technological advances to modify the body or brain in hopes of creating a desired effect. This could entail introducing various entities into the body for a variety of reasons: molecules (i.e. using metabolic control for 'slimming', anti-ageing medicine to stay young or live long), electronic chips (i.e. in the brain to help one understand better or remember more, in the eyes to improve sight, etc.), bionics for increased power, or all other implants.

Perhaps a minor detail would be the difference between implants and transplants. The former generally take the currently-used-to state of the individual to one she/he does not know in order to experience it-picture the average person having Steve Austin's bionic ability to lift and throw heavy objects! - whereas the latter aims at bringing one back to a state she/he has always been used to but has recently lost - an elderly person having a hip replacement. The only similarity between the two is that they both augment the person's present state.

Let us get back to the robotics versus transhumanism distinction. Although different, it is important to point out that there are similarities: for both approaches, it is the desired effect that leads to the design of a new or even novel being, which means there is a certain wilfulness driving towards a new world. I do not think this drive is new; it is just the techniques used that may surprise people. Change is a concept that the notion of Man has always integrated, this is the reason we are part of the world's evolutionary cycle.

But it would seem that this short-term aspect of evolution is mainly behaviour based, thus there is limited change to the identity of what it means to be human. The concept of being human does entail a highly social element to it, as well as a cultural one: it is not in individually modifying the bodies of the members of society that one can change the relationships they enjoy or detest. This said sustained corporal change over time could well have an effect on relations in society.

\subsection{Difference and the concept of Man}

The concept of Man would of course become different, but to what extent? Perhaps the thing that society is calling out for here is a concept of humans that is more material in nature when compared to the current idea of what it is to be human. The belief that we could/should/must modify our very own physical existence may mean that the immaterial-social, psychological, cultural and spiritual-aspects of our lives have become less important to us. Would such a statement be too simplistic or is it part of our new reality? Those working in advanced Artificial Intelligence, Cognitive Robotics, Neuro-evolution, and transhumanistic-type technologies generally do not delve into the intricate questions of love, faith or the respect of the Other in society, all of which directly concern the human immaterial sphere. They are not supposed to be intimately concerned with such matters, nor are other scientific fields. One could nevertheless be very mistaken in saying that these matters are not on scientists' agendas ( $c f$. infra my mention of the advances towards this in 1. Presuppositions); how could they ever hope to do better than man if they cannot even copy these facettes of the human race? We could indeed conclude for the time being that the concept of being human today means being more physically human than 100 years ago. 


\subsection{Relation and the concept of Man}

So the concept of Man has evolved. Does this operate on the relations this concept has with other concepts in its vicinity? The concepts of Nature and Artefact would be pertinent to explore here. The fact that we today accept to tamper with mother nature's 'products' is not new but the acceptance to direct this action on our physical and cognitive existences has increased exponentially. The place of nature-highly recognised as essential-in traditional cultures would have diminished. However, one is entitled to disagree with strong statements, in which case it could only be said that our relation to nature would have been altered only slightly. The important matter is in asking why this change suddenly became necessary and what our new relation with nature, however, close it is to the last version, means to us in the future.

As for the link to the concept of artefact, the shift does seem more radical, although Man has always accepted to handle his own destiny; hence the expression 'he is a selfmade man'. The tie between Man and being man-made has been strengthened in the consciousness of members of society, perhaps paradoxically. A 'self-made man' always referred to the self-assurance, aspirations, intellectual stamina and other paraphernalia of the purely psychological composition of the individual whereas now, we are able to apply it to his physical composition. The imminence of the merger between robotic products and the physically oriented propositions of transhumanism can now be addressed as more than just an eye-opening thought. If one prefers lesser-alarming realities for measuring one's consciousness of the conceptual relation between men and artefacts, one could examine the simple layman's example of the use of steroids: first they were used practically joyfully, then considered cheating, now they are amalgamated to deadliness - and this shift happened over a relatively short period of time whilst the effects of their use remained stable. Will our judgement on what can and what cannot be considered an artefact be this rapidly affected too?

\subsection{Identity and the concept of Man}

If the relations among the adjacent concepts in the system are modified because of human modification becoming abundant, what does this bring forth for the identity of man in the ecosystem? Imagine that we welcome this slide toward the increased physical definition of Man: some serious interrogations suddenly become visible. The fact that man would have the opportunity to change the very concept of himself in this manner, and that this would have a real effect on his surroundings, proves that homo sapiens would control his own 'conceptual environment' and that the techniques discussed here would be a mere side effect of his existence (i.e. other techniques could be used to sustain the developments sought). This would mean that individuals really would have obtained an overwhelming

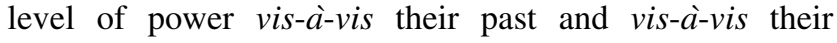
counterparts.

\section{Shouldn't we be against greater human diversity?}

In the hypothetical system just described, the weaker are bound to suffer more. Is this the type of homo sapiens we wish to become?

The identity of others (and thus Selfhood too) would be heavily affected in such a world. The identity of the Self would be equated to a very heady position-practically Godhood. But today, we do have the 'magnificent opportunity' to actually apply this ill-formed logic to our lives ourselves.

So should biodiversity include the redesign of man? As I said, the key to strengthening the argument against modifying Man has to put forth practical ideas on how and why not to modify man in such an era-many are doing it (eugenics, implants...), though perhaps not to the point of becoming cyborgs. The undemocratic nature of such practice is not stopping people because such an argument remains quite ideological for most or at least irrelevant to down-to-earth daily concerns.

The way in which they-the artificial or modified beings-would seem (too) different from the average human today is in the values they would, perceivably, be able to share and apply. Because of the hypothetical differences in the importance of (traditional) human values and their application between original men and the nonorganic originating persons, one may not wish to see these latter caring for one's children or for the elderly. One may have difficulty trusting the moral judgements of a nonnatural neighbour or artificial person. Imagine one's multiply implanted neighbour is the judge in a widely mediated homicide case; this could be a real media 'scoop', which would help picture the situation here. The same would go for our discovering the judge was a machine.

The practical measures necessary to supporting the view that biodiversity should not include the redesign of Man would entail, among other things, avoiding simulation in all its forms. This measure on simulation could be presented as just general advice, negotiations for special cases determined by a set of criteria, or out-right prohibition, according to the adopted political stance. The important aspect here is the urgency of the question as simulations are changing our vision of ourselves and our world. 


\section{Some reasons for considering greater human diversity}

If we take up the judge example once again, the fact that a human judge with silicon chip implants in the brain or a purely robotic judge can be hooked up to all the sources of jurisprudence possible in a continuous manner may one day comfort the average citizen in the decision he/it makes. It goes without saying that the sources the 'judge' has access to will have to be limited to a select official set. If accepted, this would be a very practical solution.

Those supporting the view that biodiversity should include redesigning humans have to develop strategies on the ideological and political levels in order to seriously further their cause, that of artefactualising humans, because after all, Man would be an 'artefactual object' if he was remodelled in the ways spoken of above. Furthermore, our judge example is simply that: an example. One cannot change society's strategies on a political level based on a mere practical example. Those that wish to promote the vision of a widened biodiversity in which homo sapiens would be one of the species involved would have to either directly modify the moral position of humans in the world equilibrium (difficult?) or show the strategic advantages to becoming robotic individuals (acceptable?), transhuman or posthuman (meaningless?). This may help people reexamine their traditional stances. It may help here if I make things explicit; the judge example would be a very practical solution, if accepted by all or by the majority, as long as average citizens are consulted.

Looking at the transhumanist movement will reveal that the values put forth, whether one sees them to be acceptable or not, are done so within the framework of specific basic conditions according to Bostrom (2005), of Oxford University: 'Global Security, Technological Progress, Wide Access'. ${ }^{1}$ Any sensible being shares these conditions and would like to have them protected, so the movement is not so off-tilt as some might say it to be. Have we not collectively been tampering with nature for a long time already? Man has always had the tendency to 'diversify' in one way or another, more on moral grounds than on physical ones.

Accepting to go along with such change would be a strategic move if it were to be used to unite people, communities, etc. Allowing only weaker members of society to better themselves would enable them to gain back their dignity. But would creating laws prohibiting naturally endowed persons access to changes be unfair? It is clear

\footnotetext{
1 Bostrom's article culminates in a "Table of Transhumanist Values", cf. Bostrom (2005), "Transhumanist Values", Journal of Philosophical Research, Special Supplement on 'Ethical Issues for the Twenty-First Century', p. 13.
}

that if the biodiversity of man is to be accepted by the average citizen, any sensible discourse on the matter would have use the legal/moral or non-physical level as its cornerstone.

When one considers the argumentation necessary to change things, it is tempting to just say that the physical aspects of human life are quite malleable in comparison with its non-manifest 'components'. But Bostrom gives us an indication of the little our considering transforming human beings entails and where to look for inspiration to change mindsets. In his own words, ${ }^{2}$ he mentions that the necessary ideals are found outside of our bios. We must therefore act on our logos to better fathom the advent of change. It is only if we focus on human reason that we will be able to accept our own redesign.

\section{Dialogue for dealing with the cultural shift towards the artificial}

The reader may find that I fail to correctly transcend the practical aspects of modifying man to develop sound arguments on the ideological and political levels of why to expand human diversity. However, pulling one way or another was not the goal here. The current discussion in this area of thought reminds me of Ricœur's (Changeux and Ricœur 1998) stance on the impossible adjustment between our finite body and our reason being infinitely open. Although the two levels of discourse are complementary to one another, their refusal to blend is what leads to our mistakes, our miscalculations, etc. and renders the whole process of decision-making fallible. This partially because we find ourselves before dilemmas such as the one in this question: should the 'ideal' humanoid have all the weakness man has? Do people need to be more machinelike?

Today it is clear that a certain number of values are perceived by at least some people as lost. According to Mukherjee (2007) of the Centre for Human Values at the Indian Institute of Management in Calcutta, the distinction between necessity and luxury has been greatly blurred by the effects of globalisation. He states that human consciousness is spellbound at the marvels of modern technology [...]. Caught as if in a trance, in the maze of

\footnotetext{
"The realm of posthuman values does not entail that we should forego our current values. The posthuman values can be our current values, albeit ones that we have not yet clearly comprehended. Transhumanism does not require us to say that we should favour posthuman beings or human beings, but that the right of way of favouring human beings is by enabling us to realise our ideals better and that some of our ideals may well be located outside the space of modes of being that are accessible to us with our current biological constitution". $C f$. Bostrom N., ibidem, p. 8.
} 
ceaseless activity at an alarming pace, hardly do we feel the need or urgency to reflect on such deeper questions as the purpose of life and the meaning of our actions. ${ }^{3}$ The 'religion' of simulating or modifying oneself will be the inspiration of a grassroots industry, if it is not already. I do hope to have provided elements essential to engaging dialogue on the higher-order matters herein addressed; taking action in the future depends on the knowledge we are able to create through dialogue. Grassroots industry based on a religion of simulating or modifying oneself obviously entails that one transcends the opposing standpoints presented here: either being for or against modifications to elements that do not originate in the initial material used, for example, injecting human entities into the machine or injecting mechanistic entities into the human body ( $c f$. the writings of Warwick 2004). New forms of organisations need to be driven by vigilance either to protect the unchanged or to accompany the being, whatever he, she or it is through the modifications.

\section{References}

Bostrom N (2005) Transhumanist Values, Journal of Philosophical Research, Special Supplement on 'Ethical Issues for the TwentyFirst Century', Charlottesville VA: The Philosophy Documentation Centre

Changeux J-P, Ricœur P (1998) La nature et le règle. Ce qui nous fait penser. Odile Jacob, Paris
Droit R-P (2005) “Dialoguer avec tous, et d'abord avec soi”, dossier 'Disparition: Paul Ricœur, Philosophe de tous les dialogues', Le Monde, 22-23 mai [Paul Ricœur died on the 20th of May]

Esquith S (2005) Technology and democratic political education: simulation vs. re-enactment, Society for Philosophy and Technology, The American Philosophical Association, Central Division Meeting, 27-30 April 2005 Chicago, Illinois

Jacques F (1979) Dialogiques, Recherches logiques sur le dialogue. PUF, Paris

Mukherjee S (2007) Dialogues from the Land of Love and Death, AI and Society, No. 21, pp 121-140

Quine WVO (1960) Word and object. The MIT Press, Cambridge

Schmidt CTA (2005) Of robots and believing, minds and machines. Journal for artificial intelligence. Philosophy and Cognitive Science, Kluwer

Schmidt CTA (2007) Redesigning man?. In: Vermaas PE, Kroes P, Light A, Moore SA (eds) Philosophy and design: from engineering to architecture, Springer Science, Dordrecht, pp 199-206 [an alternate account and goal of the research examined herein]

Schmidt CTA (2007) Future human intellect. speculations on the nature of knowledge transfer, 'Keynote Address' international conference entitled human being in contemporary philosophical conceptions, laboratory for philosophical anthropology research, faculty of philosophy and social technologies, Volgograd State University, Russia, May 28-31

Schmidt CTA, Kraemer F (2006) Robots, Dennett and THE Autonomous. A terminological investigation, minds and machines. Journal for Artificial Intelligence, Philosophy and Cognitive Science, Vol. 20 No. 1, Kluwer/Springer

Turing A (1950) Computing machinery and intelligence, Mind, vol LIX No. 236

Warwick A (2004) I, Cyborg, University of Illinois Press

\footnotetext{
${ }^{3}$ Cf. Mukherjee S. (2007), "Dialogues from the Land of Love and Death", AI \& Society, n 21, p. 122.
} 